\title{
Therapeutic effects of aquatic exercises on a boy with Duchenne muscular dystrophy
}

\author{
Hakan Atamturk, ${ }^{1, *}$, Arda Atamturk ${ }^{2}$ \\ 'Department of Physical Education, Faculty of Sports Sciences, Near East University, North Nicosia, Northern Cyprus \\ ${ }^{2}$ Faculty of Medicine, Near East University, North Nicosia, Northern Cyprus
}

Participation in physical activities benefits individuals with disabilities in terms of addressing their social and psychological needs in order for the purposes of quality living. This study reports the findings from a case study conducted with a boy who has Duchenne muscular dystrophy (DMD) in a swimming pool located in the campus of a private university in North Cyprus. The current study reports the adjustments made in the swimming pool in accordance with the needs of the participant, how service quality was increased to cater for these needs and in what ways the participant benefited from the aquatic program. This

\section{INTRODUCTION}

Performing physical activities is vital for both body and soul. Being physically active contributes to feelings of health, wellness and a high quality of life (Hall, 2005). Research indicates that physical activities impact teenagers' social relations with their peers and parents (Faigenbaum, 2000). Further, empirical studies suggest a negative correlation between physical activities and anxiety, depression and stress. When physical activities are performed, for instance, the levels of anxiety, depression and stress decrease. Despite this inverse relationship, there is a positive correlation between physical activities and self-respect and self-perception (Berger and Owen, 1983). Owing to these numerous benefits, physical activities should be a part of the routine of the disabled. Leading a quality life is the ultimate aim of most people who are health conscious. One way to increase quality of life is to be involved in a physical activity (Powell and Pratt, 1996). Lack of physical activity is likely to make way to such poor health problems as obesity, back and joint pain (Kiess et al., 2001). qualitative investigation aims to shed light onto how aquatic therapy has affected the boy with DMD physically, psychologically, and socially from the parents' perspectives. The results revealed that aquatic therapy had beneficial effects on the participant with DMD in terms of socialization, relaxation, quality of life and self-perception.

Keywords: Aquatic therapy, Swimming for the disabled, Functional ability, Quality of life
Swimming as a recreational activity offers considerable potential for individuals with disabilities to engage in active lifestyles. Differing from other aerobic activities, swimming is less demanding when performed as a recreational activity since swimming does not overload muscles or joints. On the contrary, it benefits the body in terms of relaxation and reduces the stress on joints (Archer, 2002). For this reason, it is one of the most preferred activities amongst people with sedentary lifestyles. Swimming is also beneficial in terms of losing weight, keeping fit, building muscles and enabling individuals with physical disabilities with fine and gross motor development. It is evident that impairments may pose severe challenges preventing the disabled from performing demanding sports.

In addition to physical benefits, swimming is good for mental health as well since it makes individuals feel refreshed and relaxed. Due to their disabilities, individuals may feel less valued, less capable and less confident. Failure in integrating disability into their lives affects how they perceive themselves, their capabilities and self-worth (Lutz and Bowers, 2005).
${ }^{*}$ Corresponding author: Hakan Atamturk (iD https://orcid.org/0000-0003-4196-436X Department of Physical Education, Faculty of Sports Sciences, Near East University, North Nicosia, Northern Cyprus, Lefkosa Mersin 10 Turkey

Tel: +90-5428612604, Fax: +90-3922236461, E-mail: hakan.atamturk@neu.edu.tr Received: July 25, 2018 / Accepted: August 16, 2018
This is an Open Access article distributed under the terms of the Creative Commons Attribution Non-Commercial License (http://creativecommons.org/licenses/by-nc/4.0/) which permits unrestricted non-commercial use, distribution, and reproduction in any medium, provided the original work is properly cited. 
Research shows that children with disabilities benefit from swimming with regard to social and psychomotor skills (Conaster, 2007). Boys with Duchenne muscular dystrophy (DMD) are no exception. As DMD patients suffer from gradually weakening muscles, they are advised to swim by their doctors in order to strengthen their muscles without putting pressure on them. There is a plethora of clinical studies conducted with DMD patients; however, there is a lack of research investigating the therapeutic effects of physical activities like swimming on individuals with DMD. In this respect, this study fills a gap in literature and provides a standpoint for future research.

Disability is defined as any kind of physical or mental impairment which prevents individuals from performing expected roles and tasks (Segen, 2002). Integration of physical activity into the lives of individuals with disabilities has been investigated by a few studies. Some of these studies have examined how physical activities add to self-perception (Huang and Brittain, 2006). Others, on the other hand, have focused on quality of life (Giacobbi et al., 2008) and social aspects (Hanson et al., 2001).

Engaging in a physical activity is a major contributor to socialization of the disabled. While performing activities, they can have the opportunity to socialize with their coaches and peers, which is highly beneficial for their emotional well-being. With regard to sport socialization, Ruddell and Shinew (2006) note that sports can be regarded as a socializing factor which contributes to the development of team skills and fosters many skills valued in society.

DMD is a genetic $\mathrm{X}$ chromosome-linked recessive myopathy and it affects about one out of every 4,200 live-born boys (van Essen et al., 1992). The disorder which affects boys only occurs because of a problem with the gene that makes dystrophin. Without dystrophin, the muscles break down making the skeletal muscles weak and leading to damage and eventual death of muscle cells. Symptoms begin when children are around 5 years old. At age five, pelvic muscles start weakening and gradually all muscles begin to weaken. The progressive muscle weakness is apparent in the shoulders, back, arms, and legs. A child with DMD has problems with balance due to unhealthy muscles. For this reason, children have trouble walking, climbing up stairs and rising from the ground. The disease tends to progress rather fast and thus a child with DMD is usually confined to a wheelchair by age 12 .

There is no cure for the disease unfortunately. However, functional abilities can be improved and preserved (Eagle, 2002). Delaying the loss of functional abilities is regarded as an important goal in managing boys with DMD as it may optimize indepen- dence (Jansen et al., 2010). As argued by Jansen et al. (2010), limited physical and social possibilities result in a secondary reduction of physical activity in the lives of the individuals with DMD. Jansen et al. (2010) propose physical training to oppose the secondary deterioration of muscle tissue and the loss of functional abilities as a result of disuse. In order to keep DMD patients physically active, swimming as a recreational activity is a great option since swimming is good for improving muscle and joint function. Besides, swimming when performed as a recreational activity is a kind of low-intensity activity. In addition to its being low-intensity, swimming is a nonweight bearing physical activity which does not put extra pressure to muscles or joints. Jansen et al. (2010) advise ambulatory boys to perform "voluntary (eventually mechanically-assisted) active exercises (such as swimming) and to avoid eccentric exercises" in accordance with the international guidelines. Eccentric exercises may injure the contractile and cytoskeletal components of the muscle fibers, which may have deleterious effects resulting in muscle deterioration (Markert et al., 2011). Yiu and Kornberg (2015) do not recommend high-resistance strength training but submaximal aerobic exercises, such as swimming. DMD patients do not tend to participate in physical activities. Due to the gradual progress of the disease, while younger patients can do certain moves using fine and gross motor skills in the early stages, it gets difficult to do most moves in later stages. For this reason, younger individuals with DMD are more likely to participate in physical activity than older Duchenne's patients (Bendixen et al., 2012).

Most DMD patients die in their late teens or early twenties resulting from weakened diaphragm and other respiratory muscles by the disease (Petrof, 1998). Hence, the focus of some studies is to strengthen respiratory muscles so as to enhance respiratory ability. Fragala-Pinkham et al. (2008) have found aquatic exercise has fostered cardio respiratory endurance.

From parents' perspectives, leisure activities are useful since they reduce stress and provide relaxation but participation in such activities is not possible all the time due to time constraints, financial burden, and lack of support (Shikako-Thomas et al., 2008). Lack of energy is another reason for decreased participation. As argued by McDonald (2002) motivation to participate may be lost by muscle weakness and fatigue, which may negatively affect quality of life.

Parents whose children are diagnosed with DMD experience various challenges. Knowing that DMD is lethal is already devastating. In addition to this, since the disease is genetic and that mothers transfer the mutation responsible for the disorder to their 
sons, mothers blame themselves. Stress is another factor that parents have. Nereo et al. (2003) have found that stress is high for mothers of boys with DMD. The aim of the current study was to explain the adjustments made in an Olympic swimming pool to cater for the needs of a physically disabled boy, explore his experiences in swimming as a recreational activity and investigate the impact of this activity on his physical and psychological health.

\section{MATERIALS AND METHODS}

In order to fulfill the research aim which was to investigate the therapeutic effects of aquatic exercises on a boy with DMD qualitative method of inquiry was adopted. The rationale for employing such a method in this case study was that it worked well with small scale studies and provided deeper insights into participants' perspectives.

\section{Case description}

Ali (pseudonym) was particularly selected to be studied in this study since his experiences with aquatic exercises were thought to advance new understandings about the benefits of aquatic exercises for DMD patients. Ali was diagnosed with DMD and he was the only DMD patient registered for the pool since when the pool was built which was in 1997. Since the pool was located in Nicosia which was a small city with a population of 94.824 in north Cyprus, such a case was unusual for the staff. The staff was not trained and the swimming pool was not disabled friendly as a building. Alarmed by the demand of the parents for one on one swimming classes, the manager of the pool, who was the first researcher called for a meeting with the three fulltime and 21 part time swimming coaches. Osman (pseudonym) who was a full-timer volunteered to teach Ali. Arda who was the second researcher was an assistant swimming coach and he volunteered to help Osman. They all read the articles shared by the first researcher about DMD patients and they consulted the parents as well about Ali's needs. The parents were invited to the pool to make the necessary adjustments. Upon the parents' evaluation of the pool, it was found that entrance to the pool and going down to the showers and to the changing rooms were going to be challenging for Ali. The pool was a three-storey building with the showers and changing rooms on the ground floor, the reception on the first floor and a cafe on the third floor. When entering the building, there is a reception desk. There is a VIP entrance door on the right of the reception desk. Swimmers and the staff were not allowed to use this door since everyone had to take a shower before entering the pool. The other two doors leading to the pool area were on the right and left sides of the main entrance. All staff and swimmers who had to use these doors leading to the showers and changing rooms had to descend 18 steps on both sides. Seeing this, the parents were disappointed because Ali had problems with ascending and descending stairs. This problem was solved by the manager by allowing Ali to use the VIP entrance door. The other problem concerning the changing rooms was solved by purchasing a wooden folding screen and placing it on the right of the door near the place where the arm-floats, pull buoys and kickboards were kept.

The pool was an Olympic swimming pool located in the campus of a private university. The pool charged fees for the locals who wanted to use the pool. Due to the socio-economic status of the family, some adjustments were also made in terms of the fees. The first researcher prepared the lesson plans for each swimming session for 8 weeks. Each course was designed as a 45 -min session which covered the moves a typical 6 year old does. Although all adaptation exercises were included, the level of difficulty of the exercises was lowered. The sessions were scheduled at half-past two because of two reasons. The first reason was that it was at the parents' convenience since they were both state school teachers who stopped work at one o'clock. The other reason was that the pool was very crowded with children after four and that Ali had problems with balance and tended to stumble. He had to walk on the pool area albeit with the help of the swimming assistant to go to the toilet. He would be safer with not many children around. Once the amendments and the adjustments were made, the staff was ready for Ali.

Soon after arriving at the pool Ali was introduced to his swimming coach. The parents were worried due to the fact that it was an aquatic sport encompassing the danger of drowning. Upon their request, Ali was not assigned to a group but he would learn swimming one on one. Ali was 6 years old. As his history revealed by the mother noted, when he was three, the parents noticed something wrong with him. More specifically, they were in the playground and when he could not climb up the slide, the parents got worried and took him to the pediatrician who advised them to see a neurologist. Then, he was diagnosed with DMD, which was devastating for the family. After a period of denial, disbelief, selfblame, strong anger and sorrow, they started to read about this disease. It was even more saddening to find out that there was no treatment and that it was lethal. Seeking to find ways to extend the period which Ali could use his functional abilities, they were advised by the neurologist to register Ali for the swimming pool. 
Ali seemed worried initially so his mother was allowed to sit on a bench in the pool area. The mother helped Ali change into his swimsuit behind the folding screen. When Ali needed to, Arda took Ali to the toilet holding his hand. Arda helped Ali put on his swimming cap and arm-floats. Ali got into the pool with Osman, and Arda was in the pool area giving them the equipment needed and sometimes Arda took over and Osman was in the pool area and Arda was in the pool with Ali.

Ali practised the activities that were tailored for him. The activities targeted back, arm, leg and chest muscles. It was not designed like a rigid training program for swimmers but it was designed like a game so that Ali would feel like he was playing. The breathing exercises aiming to improve respiratory system in general and respiratory muscles in particular were included and Ali was quite good at them. He took a deep breath with his head above the water and putting his head into the water made bubbles, which he really liked. He could do the required leg and arm moves roughly. When he was face down in water he was unable to turn his head neither left nor right. He was able to do them with help. He liked playing with the ball. Throwing and catching the ball was fun for him.

Ali had these swimming sessions twice a week. As told by the mother, he was looking forward to his swimming classes. Starting from the first session onwards, Ali developed a good relationship with Osman and Ali. When the parents were not available, for example, Ali called them to drive him to the pool. The staff and the receptionists were also fond of him. The father noted that they felt at home in the pool.

The warm-up activities were more like adaptation activities, breathing and stretching exercises, which lasted around ten minutes. Then, Ali moved to using large body movements aiming at gross motor development, which took 20 min followed by cooldown exercises, which took $10 \mathrm{~min}$. The exercises targeting gross motor development were more challenging so during these exercises whenever Ali was tired he took a break for $2 \mathrm{~min}$.

The first researcher being the manager of the pool had the opportunity to talk to the parents about Ali's experiences and progress every week. However, these were brief, informal and unscheduled meetings taking place in front of the reception or on their way to the car. They scheduled an interview for the last week of the aquatic program.

\section{Data collection procedures}

After receiving the informed consent of the parents, in-depth interviews were conducted with the mother and the father. In- depth interviews can be more revealing providing deeper insights with a small number of participants. Since there were two people to be interviewed and the issue was a sensitive one, in-depth interviews were preferred. The first researcher was the manager of the pool and the other was an assistant swimming coach at the time. Thus, the parents were always in contact with the researchers from the very beginning since when they registered for the pool. All the adjustments were made to the pool by consulting them. In the meantime, the researchers and the parents got close and developed a rapport. Thus, the interviews took place in a safe and friendly atmosphere in the manager's office. Semistructured questions were posed to elicit information about the service quality of the pool, their satisfaction level and in what ways their son benefited from aquatic exercises. Each interview lasted about 50 min and the researcher took notes.

\section{Data analysis}

In order to analyze the interview data, thematic analysis was utilized. Braun and Clarke (2006) define thematic analysis as: "A method for identifying, analyzing and reporting patterns within data." Thematic analysis allowed the researchers to have detailed description of the data.

\section{RESULTS}

The current study attempted to evaluate the impact of aquatic exercises on a boy with DMD who underwent an aquatic program designed for eight weeks. Both parents were interviewed about the ways Ali benefited from the aquatic program. Table 1 illustrates the themes emerged from the interviews.

Both parents stressed the beneficial effects of socialization on Ali. The mother told that they were grateful to the staff because they were so loving towards Ali. Ali believed that the staff were his friends. As she reported, "due to his balance problem we cannot let him go out to play football with other children. He sometimes asks why he cannot go out? It is so difficult to explain why. When I tell him he gets hurt if I let him go out, he gets angry". As he could not join other boys in most games they no longer

Table 1. Frequency distribution of the themes

\begin{tabular}{lc}
\hline Themes & Number \\
\hline Fostered socialization & 2 \\
Initiated relaxation & 2 \\
Improved quality of life & 1 \\
Enhanced self-perception & 1 \\
\hline
\end{tabular}


called him. The mother believed that Ali was safe in the pool because everyone was so caring. They made friends with Ali. The father stated Ali adored Osman and Arda. He had their phone numbers and he called them to have a chat from time to time. At one time, Ali was presented with an invitation card to a live musical show for children by Arda. Free invitation cards were sent to the pool because the university where the pool was located sponsored the musical show and they spared one for Ali. As he reported "He was all smiles. We were so moved. I think he felt valued. He said Arda likes me and I like him, too. Besides, he had an opportunity to watch the show with other children from the pool, whom he called his friends." As reported by the father, "The pool is a great place to socialize. There are many people coming and going, providing the opportunity to meet several people. Because of Ali's situation, some people stop by to talk to him. Ali likes people talking to him. He is not a shy boy. He is happy with the attention he receives and the social interaction he has."

With regard to initiated relaxation, the mother told that since the first session they felt the rehabilitative potential of swimming on Ali. She stated "This was evident in his regular sleep pattern. He slept better and got calmer. When he fell off, he cried a lot and got angry. He was sometimes aggressive towards us. He is not that aggressive since when he started swimming. At least when I explain things, he stops crying and listens to me now. I think he will be better in the future because he has changed for the better in such a short time." The father contended "In addition to muscular relaxation, swimming added to his psychological and emotional well-being. I think we could not accept this disease. Neither did Ali, I guess. Both his mother and I were stressed out because we did not know how to fight with this disease or how to manage the feelings that we had. I think Ali felt the same way. Swimming gave him something to hold on. Hope may be but he was definitely relaxed and happy after swimming sessions."

Another theme emerged from the interview data was improved quality of life. While the mother did not mention anything about how Ali's quality of life was influenced through aquatic exercises, the father told "Swimming contributed a lot to Ali's general well-being. In addition to the positive impact of swimming on Ali's muscles, it provided him with fun and enjoyment, which in turn affected his general well-being. Osman and Arda added to Ali's life as well. They enriched Ali's life. They did their best to make swimming an enjoyable activity and they played together. That's why, swimming did not mean just an activity to him but a social environment where he could play, talk and laugh. In this respect, this activity filled a gap in his life opening new doors to him. He welcomed this because he was bored at home I guess. He needed this change because sitting at home and watching TV was all about his life. On the days of his swimming classes he was waiting at the door ready to go. He was so happy and enthusiastic. He was like he found meaning in life. This decreased the stress his mother and I felt, too."

Enhanced self-perception was raised by the mother. She said "He was more confident in the water because there was no danger of falling and getting hurt in the water. When I was sitting on the bench he called to me saying "Look mum, I am diving." and I replied "Well done." When he learnt how to dive into water, he was delighted. I think he was happier in the water because he was good at doing certain moves that he could not do outside. Both Osman and Arda were encouraging and praised him when he did the moves assigned to him. This boosted his self-confidence and the praise he received from them was especially dear to him. He was free in the water, freer than he was outside water."

\section{DISCUSSION}

This case study investigated the impact of aquatic exercises on a 6 year old boy with DMD from the parents' perspectives. Overall, it was found that aquatic exercises benefited the participant in terms of socialization, relaxation, quality of life and self-perception. As suggested by the findings, Ali's social life was enriched and his social interaction was increased through the people he met at the pool. He had the opportunity to interact with not only his swimming coaches and the manager of the pool but also with the staff and other people who registered for the pool as well. This finding was in line with that of previous studies (Conaster, 2007; Hanson et al., 2001; Ruddell and Shinew, 2006) that children with disabilities benefited from swimming in terms of social skills. Another finding was that swimming initiated physical and psychological relaxation. This finding concurred with Archer's (2002) finding that swimming benefited the body in terms of relaxation and reduced the stress on joints. The finding that Ali's quality of life increased was consistent with Hall's (2005) finding that being physically active contributed to feelings of health, wellness and quality of life. Powell and Pratt (1996) regarded physical activity as a way to boost quality of life. This finding corroborated that of (Giacobbi et al., 2008) that it enhanced quality of life as well. It was found that swimming contributed to Ali's self-perception substantially. This finding went in line with Berger and Owen's (1983) finding that there was a positive correlation between physical activities and self-respect and self-perception. This finding 
also corroborated Huang and Brittain's (2006) finding that physical activities added to self-perception. As this was a case study, we could not generalize the results of the current study. However, drawing on the results of this study, we posed that aquatic exercise helped a DMD patient improve the quality of his life.

\section{CONFLICT OF INTEREST}

No potential conflict of interest relevant to this article was reported.

\section{REFERENCES}

Archer S. Aquatic exercise and arthritis. Aquat Ther J 2002;16:29-31.

Bendixen RM, Senesac C, Lott DJ, Vandenborne K. Participation and quality of life in children with Duchenne muscular dystrophy using the International Classification of Functioning, Disability, and Health. Health Qual Life Outcomes 2012;10:43.

Berger BG, Owen DR. Mood alteration with swimming-swimmers really do "feel better". Psychosom Med 1983;45:425-433.

Braun V, Clarke V. Using thematic analysis in psychology. Qual Res Psychol 2006;3:77-101.

Conaster P. Adapted aquatics and rehabilitation: a literature synthesis. Int J Aquat Res Educ 2007;1:242-254.

Eagle M. Report on the muscular dystrophy campaign workshop: exercise in neuromuscular diseases Newcastle, January 2002. Neuromuscul Disord 2002;12:975-983.

Faigenbaum AD. Strength training for children and adolescents. Clin Sports Med 2000;19:593-619.

Fragala-Pinkham M, Haley SM, O'Neil ME. Group aquatic aerobic exercise for children with disabilities. Dev Med Child Neurol 2008;50:822827.

Giacobbi PR Jr, Stancil M, Hardin B, Bryant L. Physical activity and quality of life experienced by highly active individuals with physical disabilities. Adapt Phys Activ Q 2008;25:189-207.

Hall E. The entangled geographies of social exclusion/inclusion for people with learning disabilities. Health Place 2005;11:107-115.
Hanson CS, Nabavi D, Yuen HK. The effect of sports on level of community integration as reported by persons with spinal cord injury. Am J Occup Ther 2001;55:332-338.

Huang CJ, Brittain I. Negotiating identities through disability sport. Sociol Sport J 2006;23:352-375.

Jansen M, de Groot IJ, van Alfen N, Geurts ACh. Physical training in boys with Duchenne Muscular Dystrophy: the protocol of the No Use is Disuse study. BMC Pediatr 2010;10:55.

Kiess W, Galler A, Reich A, Müller G, Kapellen T, Deutscher J, Raile K, Kratzsch J. Clinical aspects of obesity in childhood and adolescence. Obes Rev 2001;2:29-36.

Lutz BJ, Bowers BJ. Disability in everyday life. Qual Health Res 2005;15: 1037-1054.

Markert CD, Ambrosio F, Call JA, Grange RW. Exercise and Duchenne muscular dystrophy: toward evidence-based exercise prescription. Muscle Nerve 2011;43:464-478.

McDonald CM. Physical activity, health impairments, and disability in neuromuscular disease. Am J Phys Med Rehabil 2002;81(11 Suppl): S108-120.

Nereo NE, Fee RJ, Hinton VJ. Parental stress in mothers of boys with duchenne muscular dystrophy. J Pediatr Psychol 2003;28:473-484.

Petrof BJ. The molecular basis of activity-induced muscle injury in Duchenne muscular dystrophy. Mol Cell Biochem 1998;179:111-123.

Powell KE, Pratt M. Physical activity and health. BMJ 1996;313:126-127.

Ruddell JL, Shinew KJ. The socialization process for women with physical disabilities: the impact of agents and agencies in the introduction to an elite sport. J Leis Res 2006;38:421-444.

Segen JC. Concise dictionary of modern medicine. New York: The McGraw-Hill Co.; 2002.

Shikako-Thomas K, Majnemer A, Law M, Lach L. Determinants of participation in leisure activities in children and youth with cerebral palsy: systematic review. Phys Occup Ther Pediatr 2008;28:155-169.

van Essen AJ, Busch HF, te Meerman GJ, ten Kate LP. Birth and population prevalence of Duchenne muscular dystrophy in The Netherlands. Hum Genet 1992;88:258-266.

Yiu EM, Kornberg AJ. Duchenne muscular dystrophy. J Paediatr Child Health 2015;51:759-764. 